\title{
The success in the short-distance communication for mating does not depend on chemical signals in the crustacean decapod Procambarus clarkii (Girard, 1852)
}

\author{
Stefania Peddio, ${ }^{1}$ Giorgia Sollai, ${ }^{1}$ Cinzia Podda, ${ }^{2}$ Giacomo Frau, ${ }^{2}$ Francesco Palmas, ${ }^{2}$ Andrea Sabatini, ${ }^{2}$ Roberto Crnjar, ${ }^{1}$ \\ Paolo Solari ${ }^{*}$
}

${ }^{1}$ Department of Biomedical Sciences, Section of Physiology, University of Cagliari, University Campus, S.P. 8, 09042 Monserrato (CA), Italy; ${ }^{2}$ Department of Life and Environmental Sciences, University of Cagliari, Via Fiorelli 1, 09126 Cagliari, Italy

\begin{abstract}
Pheromone-driven sex recognition has been widely documented in crayfish and a great deal of evidence supports the involvement of pheromones in their mating behaviour. This study investigates whether sexual interaction and mating success in the red swamp crayfish Procambarus clarkii are dependent on short-distance chemical communication between sexes, mediated by urine-borne pheromones. We compared the mating behaviour of intact animals that could release urine to chemically communicate in a natural way with that of urine-blocked animal pairs, for which chemical communication was precluded. Our results show that urine-borne pheromones are not critical for the reproductive success of $P$. clarkii, at least over the short-range distance $(<1 \mathrm{~m})$ considered in this study, during which the animals were confined in a restricted tank, facing one each other, and thus able to promptly mate. Under these experimental conditions, a lack of urine release neither precluded the occurrence, nor affected the duration of the different phases of mating behaviour. We conclude that short-distance chemical communication in $P$. clarkii is not a prerequisite for mating, and suggest that it could be affected by alternative sensory modalities, likely vision and/or acoustic signalling.
\end{abstract}

\section{INTRODUCTION}

The use of chemical cues by animals is widespread in all environments, including freshwater habitats, where changes in behaviour after the detection of waterborne compounds have been extensively documented for many species and in many behavioural contexts (Wyatt, 2014).

Like other decapod crustaceans, crayfish rely on waterborne chemical signals to produce appropriate behavioural responses, such as spatial orientation, social communication, predator avoidance, identification of suitable habitats, location of food resources and sex recognition (Breithaupt and Eger, 2002; Grasso and Basil, 2002; Bergman and Moore, 2005; Aquiloni et al., 2009; Berry and Breithaupt, 2010; Breithaupt, 2011; Schmidt and Mellon, 2011; Solari et al., 2015, 2017, 2018). Discrimination of different stimuli is mediated by peripheral chemoreceptors grouped within sensory hairs called sensilla, which are typically located on the cuticles of cephalothoracic appendages like antennae, maxillipeds (mouthparts) and especially antennules and pereiopods (major claws and walking legs) (Schmidt and Mellon, 2011).

Pheromone-induced sex recognition, in particular, has been widely documented in different crayfish species and supports the involvement of pheromones in some aspects of crayfish sexual behaviour. For instance, pioneering studies have reported chemoreception and pheromones for sex discrimination in the red swamp crayfish Procambarus clarkii (Girard, 1852) having intact and functional antennules (Ameyaw-Akumfi and Hazlett, 1975, Dunham and Oh, 1992). Chemical detection of sex was reported for the genus Orconectes as well (Hazlett, 1985; Simon and Moore, 2007), and the presence of a sex pheromone released by mature females to stimulate courtship and mating behaviour in males was also described in the signal crayfish Pacifastacus leniusculus (Stebbing et al., 2003). Additionally, by using urine blocking protocols and visualization techniques with fluorescein dye, urine released anteriorly through a pair of nephropores into water currents generated by the animals themselves was shown to be the source of the pheromone signals (Simon and Moore, 2007; Berry and Breithaupt, 2010). In decapods, as in other crustaceans, the nephropores can be opened and closed by a sphincter muscle (Bushmann and Atema, 1996; Subramoniam, 2016) controlling modality and timing of pheromone release. Chemoreceptors housed in the antennular flagella were reported to be, in most cases, responsible for pheromone detection (Tierney et al., 1984); the major chelae were also suggested as possible, alternative sites of sex pheromone discrimination (Belanger and Moore 2006). However, a number of studies on the use of pheromones in crayfish mating behaviour produced contradictory results, suggesting that crayfish do not necessarily communicate their sex chemically (Itagaki and Thorp, 1981; Thorp, 1984). Other studies on $P$. clarkii, based on ablation experiments in both males and females, showed that the presence of antennules is not necessary for mating behaviour (Corotto et al.,1999). Recent evidence suggests that females of $P$. clarkii make use of combined visual and chemical information to more easily identify larger males and to discriminate between individuals of the opposite sex, and also tactile sensory input during physical interactions seems to provide crucial information to the female for assessment of male quality (Aquiloni and Gherardi, 2008; Aquiloni et al., 2009). 
Based on these considerations and given the lack of information in the literature about the spatial range of pheromone action, the aim of the present study was to ascertain whether mating success in the red swamp crayfish is strictly dependent on short-distance communication between sexes, as mediated by urineborne pheromones; that is, when the animals are in close proximity in a confined environment and therefore ready to start sexual interactions. Specifically, we measured the duration of the different phases of reproductive behaviour in intact animals, which could eventually release urine in order to chemically communicate in a natural way (control group), and compared the results with the duration of the corresponding phases in urine-blocked animals, for which chemical communication was precluded.

\section{METHODS}

\section{Animal collection and rearing conditions}

Adult red swamp crayfish $P$. clarkii of both sexes, 35$40 \mathrm{~mm}$ in carapace length, were collected using a backpack electrofishing unit (5.2-2.8 A, 230-400 V, 1300 W) in Molentargius-Saline Regional Natural Park (Southern Sardinia, Italy) during the spring season of 2018-2019. The crayfish were kept in Plexiglas ${ }^{\circledR}$ tanks (100 cm long, $50 \mathrm{~cm}$ wide, $20 \mathrm{~cm}$ deep) containing $60 \mathrm{~L}$ of aerated and bio-conditioned (Aquasafe, Tetra, Melle, Germany) tap water (hereafter referred to as tap water), at $22-23^{\circ} \mathrm{C}, 16 \mathrm{~h}$ light $/ 8 \mathrm{~h}$ dark photoperiodic regime, and fed with lettuce, squid or a highly appetitive commercial pellet food (Shrimps natural, SERA, Heinsberg, Germany) three times a week. Uneaten food was always removed within $1 \mathrm{~h}$ of delivery. Individuals were kept separate to avoid any reciprocal exposure of males and females and to prevent attacks or cannibalism.

\section{Urine blocking technique}

To examine the role that the urine-borne compounds may play in sexual interactions occurring during reproduction, with special regard to the pheromone(s), treated crayfish nephropores were closed, thus blocking urine release, in both sexes $3 \mathrm{~h}$ prior to experimentation, according to the procedure adopted for Pacifastacus leniusculus (Berry and Breithaupt, 2010). Practically, crayfish were removed from their tanks and immobilised, and nephropores were blocked by attaching a small piece of silicon tubing (5 mm length $\mathrm{x} 1.9 \mathrm{~mm}$ diameter) to the shell surface surrounding each nephropore using cyanoacrylate glue (Loctite, Super Attak Power Flex). To be sure on the tubing functionality, an additional cyanoacrylate layer was applied around the tube and allowed to dry. The open end of the tubing was sealed with a plasticine plug and reinforced with cyanocrylate glue. Dye tests were also performed in order to ensure that the nephropore block was sufficient to prevent any urine release during crayfish interactions. All plugs were removed at the end of the experiments and crayfish were transferred to the holding tank. Each individual was used in only one mating experiment. Animals were not fed for a $24 \mathrm{~h}$ period preceding the experiments. The sexual maturity of the crayfish was assessed by the presence of well-developed glair glands in females and whitened gonopods in males (McLay and van den Brink, 2016).

\section{Experimental protocol}

Individuals of each sex were introduced to either side of a Plexiglas ${ }^{\circledR} \operatorname{tank}(40 \mathrm{~cm}$ long, $30 \mathrm{~cm}$ wide, $15 \mathrm{~cm}$ deep) containing $10 \mathrm{~L}$ of tap water $\left(22-23^{\circ} \mathrm{C}\right)$, separated by a central acrylic divider, and left to acclimatise for $15 \mathrm{~min}$. The divider was then lifted and animals were allowed to interact for a maximum of $4 \mathrm{~h}$. Following each experiment, the tanks and dividers were washed thoroughly. Trials were video-recorded for later analysis using a Samsung SMX-F34 (Samsung, Seoul, Korea) colour digital camera mounted above the test tank. Video recordings were analysed by an independent observer blind to the experimental treatment. The courtship behaviour of both the open-nephropore crayfish $(n=9$ pairs) and the blocked-nephropore animals ( $\mathrm{n}=8$ pairs) was recorded, analysed and categorised into the following five phases (hereafter abbreviated as $\mathrm{Ph} 1$ - Ph5; Fig. 1; Stebbing et al., 2003):

Ph1. Orientation: the male oriented and started moving towards the female, which tended to remain stationary until the male approached;

$\mathrm{Ph}$ 2. Contact: the animals met with chelae raised and the female became submissive. Mating contact was clearly distinguishable from non-mating contact, because the female did not swim away when grasped by the male;

Ph3. Pre-copulation mounting: the male grasped the female by her chelipeds, antennae or rostrum in order to climb onto her back, turn her over and to move along her body until their ventral surfaces were opposed;

Ph4. Spermatophore deposition: the male deposited spermatophores onto the female's ventral surface;

Ph5. Dismounting: after deposition, the females struggled and turned over, throwing the males off and moving away.

To assess the effect of the urine block, and therefore of the lack of pheromone communication, on the sexual interactions and mating success, the duration of each phase was measured and compared between the two experimental groups. 
All data (mean time $\pm \mathrm{SE}$ ) were subjected to one-way analysis of variance (ANOVA) with a 95\% confidence level $(\mathrm{P}<0.05)$. Data were first checked for normality and homogeneity of variance using the Kolmogorov-Smirnov and the Levene tests, respectively, which allowed us to use parametric tests. Statistical analyses were carried out using STATISTICA for WINDOWS (ver. 7.0; StatSoft Inc., Tulsa, OK, USA).

\section{RESULTS}

In terms of the duration of each of the five phases of crayfish mating behaviour (Fig. 2), we found that blocking urine release did not affect animal orientation (Ph1) $\left(\mathrm{F}_{[1.15]}=0.0916 ; \mathrm{P}=0.77\right)$, which is the initial, critical phase of the mating process, in which the crayfish begin to approach each other. In P. clarkii, this proved to be a relatively fast phase and lasted only a few minutes for both the control $(2.99 \pm 0.69 \mathrm{~min})$ and the urine-blocked animals (3.28 $\pm 0.70 \mathrm{~min})$.

The following phase, the contact between animals $(\mathrm{Ph} 2)$, was longer than the orientation phase, and was characterised by the fact that, before becoming submissive, the female exhibited an initial level of aggressiveness towards the male. Despite the great variability in the response exhibited by both of the experimental groups of animals, the duration of $\mathrm{Ph} 2$ was not affected by a lack of urine release $\left(\mathrm{F}_{[1.15]}=0.6841\right.$; $\mathrm{P}=0.42$ ).

The third phase considered was the pre-copulation mounting phase (Ph3), starting with the immobilisation
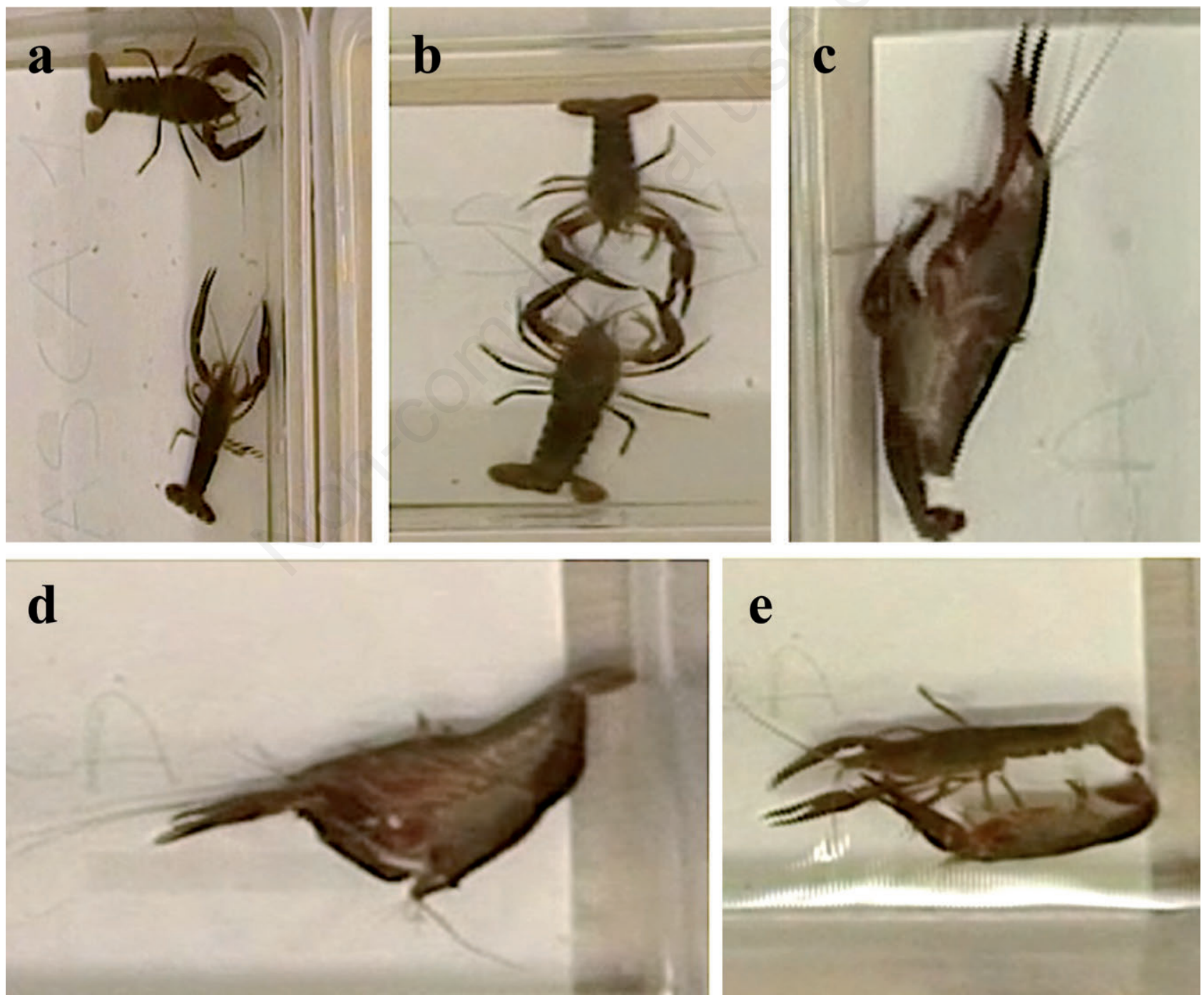

Fig. 1. Representative pictures showing the different phases of the $P$. clarkii mating behaviour considered in this study, orientation (a), contact (b), pre-copulation mounting (c), spermatophore deposition (d) and dismounting (e). 
of the female and culminating in the opposition of the animals' ventral surfaces. Overall, $\mathrm{Ph} 3$ was relatively fast and lasted only $0.63 \pm 0.10$ and $0.56 \pm 0.05 \mathrm{~min}$ in the control animals and in urine-blocked ones, respectively. Like previous phases, $\mathrm{Ph} 3$ did not depend on the release of urine and therefore on the ability of the animals to communicate chemically with each other $\left(\mathrm{F}_{[1.15]}=0.2997\right.$; $\mathrm{P}=0.59$ ).

The fourth phase $(\mathrm{Ph} 4)$, which is most critical for the success of reproductive behaviour, consisted of the gonopod-guided deposition of the male spermatophores within the annulus ventralis of the female. $\mathrm{Ph} 4$ proved to be long indeed, lasting $35.77 \pm 5.20 \mathrm{~min}$ in the control pairs and $39.19 \pm 7.93 \mathrm{~min}$ in the blocked-nephropore ones, but once again, blocking urine release did not produce any significant effect $\left(\mathrm{F}_{[1.15]}=0.1361 ; \mathrm{P}=0.72\right)$.

The final dismounting phase (Ph5) was also unaffected by a lack of chemical communication between sexes $\left(\mathrm{F}_{[1.15]}=0.4879\right.$; $\left.\mathrm{P}=0.49\right)$; females from the urineblocked group were able to struggle and turn over, throwing the males off, in a time that was comparable with that of control females.

\section{DISCUSSION AND CONCLUSIONS}

The present study shows that in the red swamp crayfish $P$. clarkii, urine-borne sex pheromones are not critical for interactions between sexes aimed at the reproductive success, at least on the small spatial scale considered; the animals were confined in a restricted environment, facing each other and ready to start mating behaviour. In fact, under these experimental conditions, the lack of urine release neither precluded the occurrence, nor affected the duration of the different phases of the crayfish mating, as the behavioural patterns of urineblocked animals were comparable to those of control crayfish, which could release their urine and therefore chemically communicate in a natural way. If the ability of these animals to identify the sex of a conspecific and to reciprocally interact for mating purposes was impaired by a lack of urine-borne chemicals, one might expect it to take longer for an animal to accomplish these tasks, therefore delaying mating or, eventually, preventing it. It is likely that the initial approach, including orientation and the initial contact between animals, are the most critical moments of sex recognition and for obtaining consent to mate, so it is in these phases that the ability to chemically communicate might play a decisive role. The duration of the contact phase, in particular, seemed to be inversely proportional to the degree of affinity between the two sexes, in such a way that the higher was the affinity between the partners, the shorter was the time to complete this phase.

In the case of $P$. clarkii, neither of these phases were significantly delayed by blocking urine, suggesting that short-distance urine-borne pheromones were not necessary for mating in these animals. In this respect, $P$. clarkii differs

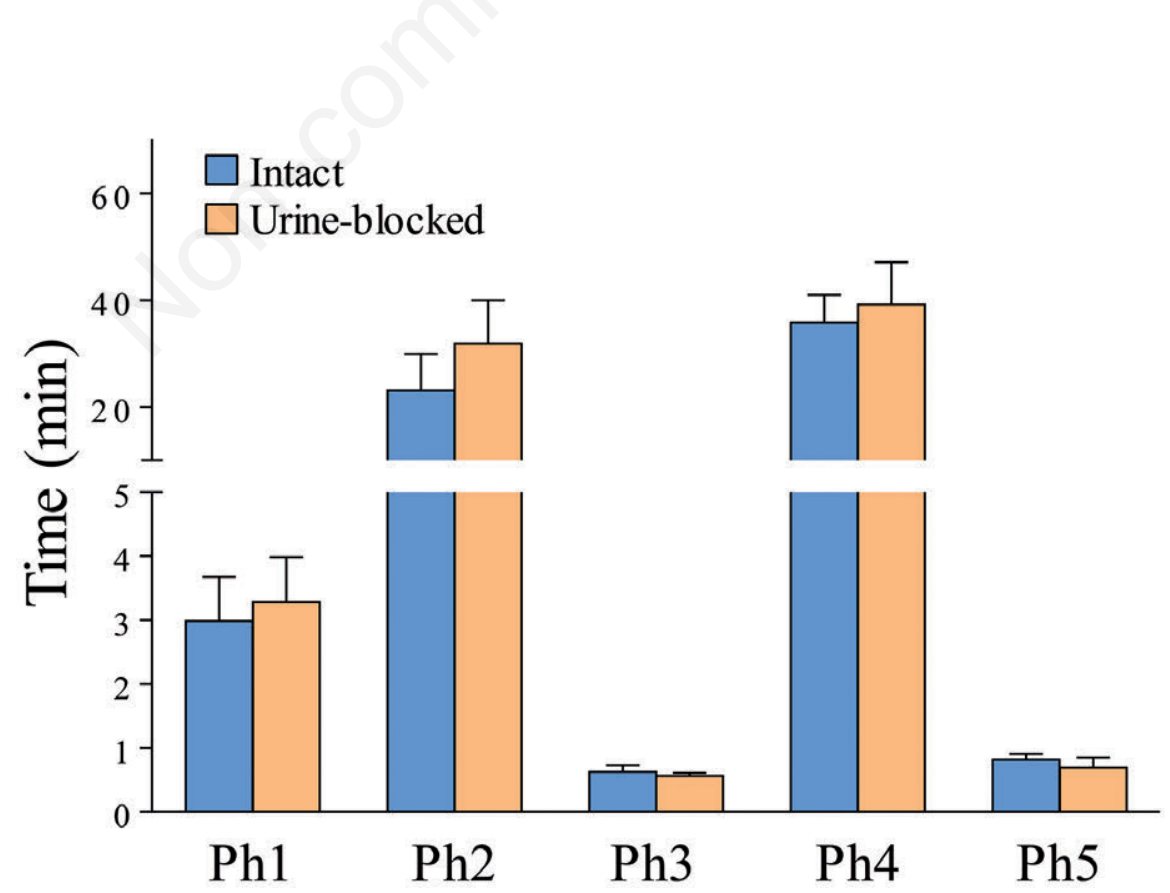

Fig. 2. Time spent ( $\mathrm{min})$ during the different phases of the mating behaviour, orientation $(\mathrm{Ph} 1)$, contact $(\mathrm{Ph} 2)$, pre-copulation mounting $(\mathrm{Ph} 3)$, spermatophore deposition $(\mathrm{Ph} 4)$ and dismounting $(\mathrm{Ph} 5)$ in the intact (control) and in the urine-blocked crayfish pairs. Values are means \pm SEM (vertical bars) from 9 intact and 8 urine-blocked animal pairs. 
from other freshwater crayfish like P. leniusculus. In fact, in the case of $P$. leniusculus, unambiguous responses such as "mating" of males with an air-stone releasing conditioned water from mature females clearly pointed to the involvement of a pheromone that induces courtship and mating behaviour in males (Stebbing et al., 2003). Furthermore, in P. leniusculus, blocking female urination prevented any male courtship behaviour, while artificial introduction of female urine was found to re-establish male mating attempts (Berry and Breithaupt, 2010). In the case of $P$. clarkii, previous experimental observations are contradictory; a number of studies documented the use of chemoreception and pheromones for sex discrimination, but only if the antennules were intact (Ameyaw-Akumfi and Hazlett, 1975, Dunham and Oh, 1992). On the other hand, it must be noted that $P$. clarkii neither communicate their sex chemically, nor does antennule loss measurably impair sex discrimination, at least when the animals are in close proximity (Itagaki and Thorp, 1981; Thorp, 1984; Corotto et al., 1999). Disregarding the different experimental designs that gave rise to these discrepancies, our findings support the hypothesis that sex discrimination and mating behaviour in P. clarkii do not necessarily involve urine-borne chemicals. Removing antennules might not necessarily lead to the same conclusions, as crayfish can use non-antennule chemoreception for sex discrimination, as suggested by Corotto et al. (1999) in $P$. clarkii and Belanger and Moore (2006) in O. rusticus.

Certainly, we cannot exclude the possibility that sex pheromones and chemical communication in P. clarkii are involved in some aspects of the sexual behaviour. This could especially hold true over the long distances, over which olfactory cues may support searching behaviour better than any other sensory modality. This is a wellknown, pheromone-guided, stereotyped behaviour for mate search, typical of many animals, including crustaceans and insects, in which it is often referred to as "calling behaviour" (Kaissling, 2014). However, when the crayfish are already in close proximity and facing one another, as in our experimental conditions, olfaction could be of less importance for sex discrimination and even redundant or easily overtaken in importance by alternative, faster methods of communication, such as visual, acoustic, or multimodal sensory inputs. In fact, it was suggested that even if they are most active at night (Penn, 1943), females of $P$. clarkii are able to combine visual and chemical information to readily identify large males and to discriminate among individuals of opposite sex; tactile input during physical interactions also seems to provide crucial information to the female for assessment of male quality (Aquiloni and Gherardi, 2008; Aquiloni et al., 2009). Similarly, it was reported that $P$. clarkii can communicate underwater by producing and detecting sounds (Buscaino et al., 2012); it is likely that this ability can also be used for sex discrimination during the initial phases of mating when the animals are already in close proximity, with no need for additional chemical communication. Further investigation is needed to determine if alternative sensory modalities, likely vision and/or acoustics, are involved in these processes.

Our results also show that the three other phases of mating studied, pre-copulation mounting, spermatophore deposition and dismounting, occurred with no delay in urine-blocked animals compared to intact animals; that is, these phases occurred regardless of the ability of the animals to exchange chemical cues. This also suggests that once mating behaviour starts, it may proceed and can be completed via a stereotyped procedure that does not require further signals.

On the whole, the five-stage mating behaviour of $P$. clarkii described here was substantially similar, from a qualitative point of view, to that exhibited by other crayfish species such as P. leniusculus, Pacifastacus trowbridgii and Austropotamobius pallipes, although the number of phases considered, three to seven, was different in the different species (Mason, 1970; Ingle and Thomas, 1974; Villanelli and Gherardi, 1998; Stebbing et al., 2003). In particular, the main phases of contact, turning, mounting, and spermatophore deposition were observed in all other crayfish species studied. Conversely, the time that $P$. clarkii took to complete the mating process, about 60-80 min, was much longer than that observed in other crayfish, 5 min for A. pallipes (Villanelli and Gherardi, 1998), 8-20 min for P. trowbridgii (Mason, 1970) and 2836 min in P. leniusculus (Stebbing et al., 2003), as in $P$. clarkii the contact and the spermatophore deposition phases took a very long time.

In conclusion, short-range sex discrimination and the occurrence of mating behaviour in the crayfish $P$. clarkii do not require chemical communication between sexes and, when the animals are in close proximity and ready to interact, they can begin and complete all phases of mating even when neither sex is able to release urineborne pheromones.

At present, we cannot ascertain if this may represent an advantageous reproductive strategy for this crayfish, but we anticipate that it could represent a way to facilitate and optimise mating for a high yield. Therefore, together with the considerable ecological plasticity, resistance, aggressiveness and bioturbation ability, this reproductive feature may increase the high invasive potential of $P$. clarkii for freshwater habitats worldwide (Gherardi, 2006; Salvadori et al., 2014, Souty-Grosset et al., 2016; Palmas et al., 2019). For these reasons, this species is now listed among the "100 of the worst" invasive species by the "Delivering Alien Invasive Species Inventories for Europe" project (DAISIE, 2009), thus requiring severe population control strategies (Manfrin et al., 2019). 


\section{ACKNOWLEDGMENTS}

This research was partially supported by the "Fondazione con il Sud", Italy (Grant No. 2015-0065). We thank Marco Melis, Department of Biomedical Sciences, University of Cagliari, for his helpful cooperation and technical support in the experimental part of the study. All applicable international, national, and/or institutional guidelines for the care and use of animals were followed.

Corresponding author: solari@unica.it

Key words: Crayfish; invasive alien species; chemoreception; pheromones; olfaction; sex recognition.

Conflict of interest: The authors declare no competing interests

Received: 11 October 2019.

Accepted: 3 December 2019.

This work is licensed under a Creative Commons Attribution NonCommercial 4.0 License (CC BY-NC 4.0).

${ }^{\mathbb{C}}$ Copyright: the Author(s), 2019

Licensee PAGEPress, Italy

Advances in Oceanography and Limnology, 2019; 10:8617

DOI: 10.4081/aiol.2019.8617

\section{REFERENCES}

Ameyaw-Akumfi C, Hazlett BA, 1975. Sex recognition in the crayfish Procambarus clarkii. Science 190:1225-1226.

Aquiloni L, Gherardi F, 2008. Assessing mate size in the red swamp crayfish Procambarus clarkii: effects of visual versus chemical stimuli. Freshwater Biol. 53:461-469.

Aquiloni L, Massolo A, Gherardi F, 2009. Sex identification in female crayfish is bimodal. Naturwissenschaften 96:103110.

Belanger RM, Moore PA, 2006. The use of the major chelae by reproductive male crayfish (Orconectes rusticus) for discrimination of female odours. Behaviour 143:713-731.

Bergman DA, Moore PA, 2005. The role of chemical signals in the social behavior of crayfish. Chem. Senses 30:305-306.

Berry FC, Breithaupt T, 2010. To signal or not to signal? Chemical communication by urine-borne signals mirrors sexual conflict in crayfish. BMC Biol. 8:25.

Breithaupt T, Eger P, 2002. Urine makes the difference: chemical communication in fighting crayfish made visible. J. Exp. Biol. 205:1221-1231.

Breithaupt T, 2011. Chemical communication in crayfish, p. 257-276. In: T. Breithaupt and M. Thiel (eds.), Chemical communication in crustaceans. Springer, New York.

Buscaino G, Filiciotto F, Buffa G, Di Stefano V, Maccarrone V, Buscaino C, Mazzola S, Alonge G, D'Angelo S, Maccarrone V, 2012. The underwater acoustic activities of the red swamp crayfish Procambarus clarkii. J. Acoust. Soc. Am. 132:1792-1798.
Bushmann P, Atema J, 1996. Nephropore rosette glands of the lobster Homarus americanus: possible sources of urine pheromones. J. Crust. Biol. 16:221-231.

Corotto FS, Bonenberger DM, Bounkeo JM, Dukas CC, 1999. Antennule ablation, sex discrimination and mating behavior in the crayfish Procambarus clarkii. J. Crust. Biol. 19:708712.

DAISIE, 2009. Handbook of Alien Species in Europe. Invading Nature: Springer Series in Invasion Ecology, 3. Springer, Dordrecht: 399 pp.

Dunham DW, Oh JW, 1992. Chemical sex-discrimination in the crayfish Procambarus clarkii: role of antennules. J. Chem. Ecol. 18:2363-2372.

Gherardi F, 2006. Crayfish invading Europe: the case study of Procambarus clarkii. Mar. Freshw. Behav. Physiol. 39:175-191.

Grasso FW, Basil JA, 2002. How lobsters, crayfishes, and crabs locate sources of odor: current perspectives and future directions. Curr. Opin. Neurobiol. 12:721-727.

Hazlett BA, 1985. Chemical detection of sex and condition in the crayfish Orconectes virilis. J. Chem. Ecol. 11:181-189.

Ingle RW, Thomas W, 1974. Mating and spawning of the crayfish Austropotamobius pallipes (Crustacea: Astacidae). J. Zool. 173:525-538.

Itagaki H, Thorp JH, 1981. Laboratory experiments to determine if crayfish can communicate chemically in a flow-through system. J. Chem. Ecol. 7:115-126.

Kaissling KE, 2014. Pheromone reception in insects (the example of silk moths), p. 99-146. In: C. Mucignat-Caretta (ed.), Neurobiology of chemical communication. CRC Press, Boca Raton, FL, USA.

Manfrin C, Souty-Grosset C, Anastácio PM, Reynolds J, Giulianini PG, 2019. Detection and control of invasive freshwater crayfish: from traditional to innovative methods. Diversity 11:5.

Mason JC, 1970. Copulatory behaviour of the crayfish, Pacifastacus trowbridgii (Stimpson). Can. J. Zool. 48:969976.

McLay CL, van den Brink AM, 2016. Crayfish growth and reproduction, p. 62-116. In: M. Longshaw and P. Stebbing (eds), Biology and ecology of crayfish. CRC Press, Boca Raton, FL, USA.

Palmas F, Podda C, Frau G, Cau Al, Moccia D, Peddio S, Solari P, Pusceddu A, Sabatini A, 2019. Invasive crayfish (Procambarus clarkii, Girard, 1852) in a managed brackish wetland (Sardinia, Italy): controlling factors and effects on sedimentary organic matter. Estuar. Coast. Shelf Sci. 231:106459.

Penn GH Jr. 1943. A study of the life history of the Louisiana red crayfish (Girard). Ecology 24:1-18.

Salvadori S, Coluccia E, Deidda F, Cau A, Cannas R, Lobina C, Sabatini A, Deiana AM, 2014. Karyotype, ribosomal genes, and telomeric sequences in the crayfish Procambarus clarkii (Decapoda: Cambaridae). J. Crust. Biol. 34:525-531.

Schmidt M, Mellon D, 2011. Neuronal processing of chemical information in crustaceans, p. 123-147. In: T. Breithaupt and M. Thiel (eds.), Chemical communication in crustaceans. Springer, New York.

Simon JL, Moore PA, 2007. Male-female communication in the crayfish Orconectes rusticus: the use of urinary signals in 
reproductive and non-reproductive pairings. Ethology 113:740-754.

Solari P, Melis M, Sollai G, Masala C, Palmas F, Sabatini A, Crnjar R, 2015. Sensing with the legs: contribution of pereiopods in the detection of food-related compounds in the red swamp crayfish Procambarus clarkii. J. Crustac. Biol. 35:81-87.

Solari P, Sollai G, Masala C, Loy F, Palmas F, Sabatini A, Crnjar R, 2017. Antennular morphology and contribution of aesthetascs in the detection of food-related compounds in the shrimp Palaemon adspersus Rathke, 1837 (Decapoda: Palaemonidae). Biol. Bull. 232:110-122.

Solari P, Peddio S, Sollai G, Masala C, Podda C, Frau G, Palmas F, Sabatini A, Crnjar R, 2018. Development of PVC dispensers for long-lasting release of attractants for the control of invasive crayfish populations. Diversity 10, 128.

Souty-Grosset C, Anastácio MP, Aquiloni L, Banha F, Choquer J, Chucholl C, Tricarico E, 2016. The red swamp crayfish Procambarus clarkii in Europe: impacts on aquatic ecosystems and human well-being. Limnologica 58:78-93. Stebbing PD, Bentley MG, Watson GJ, 2003. Mating behaviour and evidence for a female released courtship pheromone in the signal crayfish Pacifastacus leniusculus. J. Chem. Ecol. 29:465-475.

Subramoniam T, 2016. Sexual biology and reproduction in crustaceans. Academic Press, Amsterdam: 526 pp.

Thorp JH, 1984. Theory and practice in crayfish communication studies. J. Chem. Ecol. 10:1283-1287.

Tierney AJ, Thompson CS, Dunham DW, 1984. Site of pheromone reception in the crayfish Orconectes propinquus (Decapoda, Cambaride). J. Crust. Biol. 4:554-559.

Villanelli F, Gherardi F, 1998. Breeding in the crayfish, Austropotamobius pallipes: mating patterns, mate choice and intermale competition. J. Fresh. Biol. 40:305-315.

Wyatt TD, 2014. Pheromones and animal behavior: chemical signals and signatures. Cambridge University Press, Cambridge: 419 pp. 